\title{
Analysis of Influence of Price to Customer Satisfaction Based on the Prediction Models
}

\author{
Kazuhiro Esaki \\ Faculty of Science and Engineering, HOSEI University, Koganei-shi, Tokyo, Japan \\ Email: Kees959@hotmail.com
}

Received March 20, 2013; revised April 26, 2013; accepted May 11, 2013

Copyright (C) 2013 Kazuhiro Esaki. This is an open access article distributed under the Creative Commons Attribution License, which permits unrestricted use, distribution, and reproduction in any medium, provided the original work is properly cited.

\begin{abstract}
For the purpose of improvement of the sales, confirming the influence of price to the sales and customer satisfaction of the product is important. The most suitable price should be determined from the view point of customers, and it is extremely important to implement a high quality product corresponding to the real need of customers. It may have close relationship between cost and an expense to implement the individual inherent attribute of system product. Also, it may have close relationship between production cost and price of product. For the purpose of improvement of the customer satisfaction for quality of system product, the method of quantitative quality requirement and evaluation based on the ISO/IEC9126 quality model that includes six quality characteristics is widely recognized. In the precedent study, I have introduced the requirements definition method for the quality of system product based on the system quality model defined in ISO/IEC9126 and proposed the effectiveness of it statistically. In the previous study, I have also confirmed the relationship between inherent attributes of the product and quantitative result of the measured value of total customer satisfaction from the view point of six quality characteristics statistically. I performed the development of the prediction model to estimate the total customer satisfaction for the system product from the view point of inherent attribute of the product. And, I have proposed the effectiveness of application of the estimated prediction model and possibility of improvement of the total customer satisfaction of a system product. Based on the result of previous study, in this paper, I propose the result of investigation of influence of price to customer satisfaction, and the possibility of application of estimated prediction model for improvement of the total customer satisfaction of system product based on the price of product. Also, based on the result of investigation of relationship among price and inherent attributes of product, I propose the possibility of application of estimated prediction model and improvement of the price of system product from the view point of inherent attributes of product.
\end{abstract}

Keywords: Total Customer Satisfaction; Price; Cost; System; Software; Quality Requirement; Quality Evaluation; Quality Model; Quality Characteristic; Inherent Attribute; Assigned Property; Prediction Model

\section{Introduction}

The profitability of the system product is decided by the sales of the product influenced by the price and inherent attribute of the product. Furthermore, the customer satisfaction and price of product may have a big influence to the sales of the product. In order to improve customer satisfaction of the product, it is very important to determine the suitable price of product, and more attractive and cost effective products should be designed corresponding to the real customer needs during possible early stage of development. From the view point of expected profit, financial re-sources should be limited and the most suitable price should be determined from the view point of customer need and based on the consideration of reduction of cost. But it is necessary to implement the most attractive and cost effective product correspond to the real customer needs as much as possible.

Usually, relationship between sales and customer satisfaction, which is caused by the price and inherent quality of the product, is recognized closely. Also, cost of product for implementing the specific inherent attribute of product based on the consideration of customer satisfaction may have an influence to price. Furthermore, relationship between inherent attribute and price of system product may be closely recognized. In order to realize the suitable quality of product, it is necessary to grasp the quality requirements of customers for the system accurately, and the quantitative and concrete inherent quality for targets system product should be defined. 
After that, requirement of inherent attributes should be described into the quality requirement specification.

After realize cost effective and high quality product successfully, we should determine the most suitable price in order to take the much sales and profit.

If we take the wrong approach to requirement specification based on the real needs of both quality and price of system product, it may cause a big loss for a purpose of investment.

In recent years, we have been working on developing the ISO/IEC25000 (SQUARE) series [1-6] of standards for quality requirements and evaluation for system and software product for a long time in ISO/IEC JTC1 (Joint Technical Committee 1 of the International Organization for Standardization and the International Electro technical Commission) SC7WG 6 (software and systems engineering under ISO technical committee, working group six).As part of this project, we have also worked on the developments of ISO/IEC9126-1 [7] (This standard has replaced by ISO/IEC25010:2011 [8]), which is the standards to provide the supporting technology for above mentioned works and also include the quality characteristics.

For the purpose of improvement of the customer satisfaction of system product, the method of quantitative quality requirement and evaluation based on the ISO/IEC9126 quality model that includes six quality characteristics is widely recognized.These six quality characteristics are described based on the precedent study $[9,10]$, or from the view point of a stake holder's wide experiences. ISO/IEC9126-1 is defining the six quality characteristics of the system and software. This model introduced in ISO/IEC9126-1 may be formulated with almost perfect quality target establishment and evaluation perspective of the system.

Through analysing customer requirements based on these six quality characteristics, it may become possible performing complete and objective evaluation of customer quality requirements for a system/software product. However, for an evaluation of the customer satisfaction of system product, application of these quality model and independency of each quality characteristics has not been inspected and the suitability of method by using these six quality characteristics for quality requirement and evaluation has not been certified statistically.

In recent years, customers are able to purchase the products based on an increasing number of customer reviews posted on the Internet web site. Degree of customer dissatisfaction may not be accurately obtained by simply classifying negative reviews of online into the six quality characteristics.

In the precedent study, I have introduced the requirements definition method for the quality of system product based on the system quality model defined in ISO/
IEC9126 by using dissatisfaction data obtained from internet and proposed the effectiveness of it statistically.

This study focuses on negative reviews of Laptop Personal Computers (LPCs) posted by consumers and this study used the statistical analysis approach based on the previous study of software product and process improvement $[11,12]$.

In the previous study, I have also confirmed the relationships between inherent attributes of the product and quantitative result of a measured value of total customer satisfaction from the view point of six quality characteristics statistically. In addition, I performed the development of the prediction model to estimate the total customer satisfaction for the system product from the view point of inherent attribute of the product. And, I have already confirmed the causal relationships between total customer satisfaction and inherent attributes of product base on the validity of six quality characteristics and proposed the effectiveness of application of the estimated prediction model and possibility of improvement of the total customer satisfaction of a system product.

Based on the result of previous study, in this paper, I propose the result of investigation of influence of price to customer satisfaction, and the possibility of application of estimated prediction model for improvement of the total customer satisfaction of system product based on the price of product. Also, based on the result of investigation of relationship between customer satisfaction, price and inherent attributes of product, I propose the possibility of application of estimated prediction model and improvement of the total customer satisfaction and sales.

\section{Concepts}

\subsection{General Concept of Price and Sales}

Figure 1 shows the general concept about relationship between a price and other concerning factors of product.

From Figure 1, inherent attributes of product may cause a cost and customer satisfaction based on the cate-

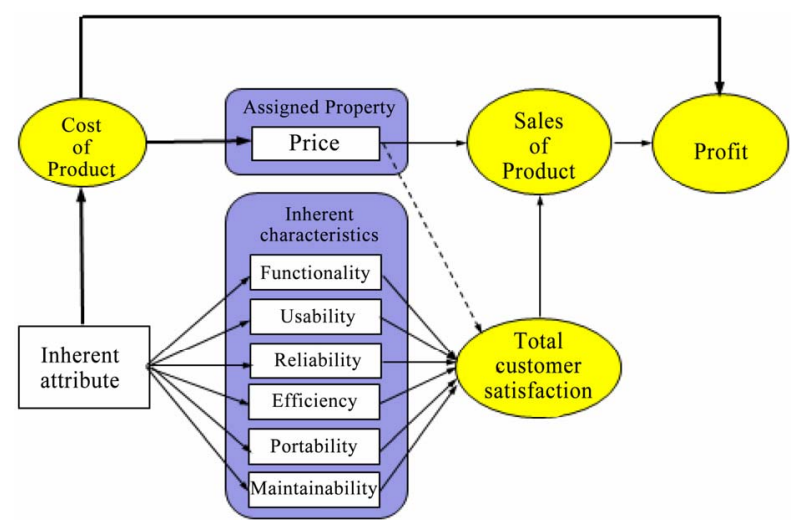

Figure 1. Basic concept of customer satisfaction. 
gorization of six quality characteristics of product. A price of product may be determined based on a cost, and the consideration of both expected sales and profitability.

On the other hand, sales of product may be influenced by both a price of product and total customer satisfaction of a product. Furthermore, customer satisfaction may be derived by a price and inherent quality of product from the view point of customer needs. Inherent quality of a product is implemented by the inherent attributes of product from the view point of six quality characteristic defined in ISO/IEC9126 quality model.

From the result of consideration of previous study, the total customer satisfaction can be constructed by using the inherent attributes from the view point of each six quality characteristics and a price of product.

\subsection{Concept of Improvement of Customer Satisfaction}

Figure 2 shows the concept of system product implementation. Customer needs include requirement of price and of inherent attributes of system product. In order to perform development, developers should specify a quality requirement based on the expected cost and the price from the view point of customer's needs at the design stage.

We should make specifications that at first we grasp the real needs of the customers at the beginning, and described the concrete inherent attribute and cost that you should realize with a product. After development, developer and customer should evaluate the target system product based on the quality requirement specification in order to assure the quality of developed product.

From Figure 2, ISO/IEC25030 [3] provides the requirements and recommendations, process for defining quality requirements specification from selected and described customer's needs based on the system product quality model include six quality characteristics described

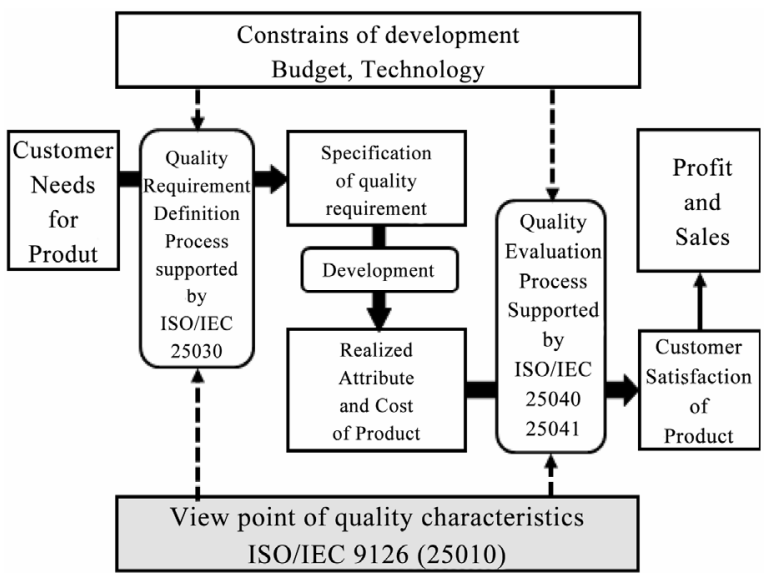

Figure 2. Concept of prediction model of customer satisfaction for system product quality. scribed in ISO/IEC9126-1, the specified quantitative quality requirements should be used as the criteria of system and software product evaluation. From Figure 2, system quality evaluation can be performed by using ISO/IEC25040 [4] and 25041 [5] based on the specified quality requirements, which are specified by using ISO/IEC25030 during system design phase.

Table 1 shows the price and the inherent attributes of the products which has used in this study. A good product is the product which is high in a sufficiency degree of quality of the product and cost effective for the customer, and it is thought that the satisfaction of the product for the customer is high. Result of decision of customer's satisfaction concerning price and inherent attribute of product may cause the purchasing of target product.

It is thought that the customer satisfaction of the product may depend on the inherent attributes and a price of a product for the needs of the customer.

A developer should achieve implementing the inherent attribute of target product based on the limited cost and specifications of system product. As a result of products development, production cost and the concrete inherent attribute of the product may be decided.

If the customer satisfaction for an inherent quality of product is high and the price of product is low, as a result, the sales of the product may increase, and it is thought that profitability can increase.

\subsection{Concept of System and Software Quality Model}

Figure 3 shows the structure of the Software Quality Model defined in ISO/IEC9126-1. Recently, ISO/IEC9126-1 have replaced by ISO/IEC25010:2011, but ISO/ IEC9126-1 is widely recognized and actually used, then this study focus on the ISO/IEC9126-1.

From Figure 3, this model includes the six quality characteristics for system and software such as Functionality, Reliability, Usability, Efficiency, Portability and Maintainability.

The Functionality can provide to achieve the ultimate objective, such as increased productivity and sustainable development of a company, and Usability provide the ease of use of the system.

Reliability and Efficiency represent the capability possessed by the system, and are the characteristic associated with sustaining the quality objectives determined by the Functionality and Usability.

Maintainability and Portability provide the adaptability for the system to adapt to changes in the system environment and the usage environment.

\section{Summaries}

This study first collects customer complaints, i.e., ex- 


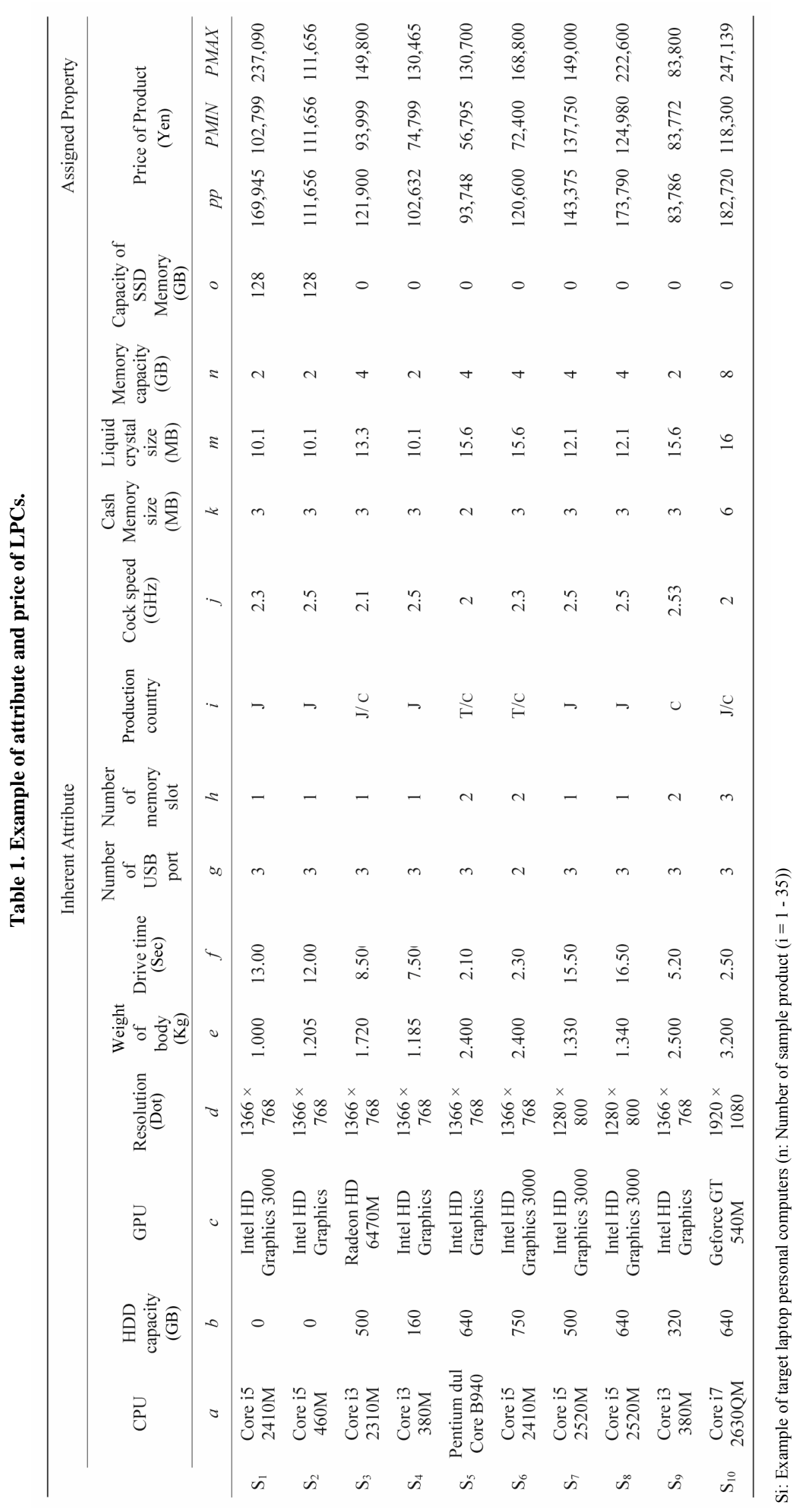


pression of customer dissatisfaction, posted on a review website where customers who actually purchased personal computer related products post their reviews as shown in Table 2.

The study, then, classifies the posted customer complaints based on the six quality characteristics defined in the ISO/IEC9126-1, obtains from questionnaires a weight for each quality characteristic to represent the importance of quality characteristic for the customer, and applies the weights to the six quality characteristics, and quantifies the degree of customer satisfaction for each quality characteristic as shown in Table 3.

This study calculates the observed total customer satis- faction by using customer satisfaction of each six quality characteristics based on the technique that I showed for the beginning in a precedent study [11].

This study second collects price of each product as as-signed property and inherent attributes of target products, i.e., CPU, HDD capacity, weight of body, Drive time, as shown in Table $\mathbf{1 .}$

The study performs correlation analysis among of the degree of price and inherent attributes of LPCs, and confirms that the attributes of them are mutual independent or not.

In addition, the study develops a model that actually predicts the degree of total customer satisfaction of the

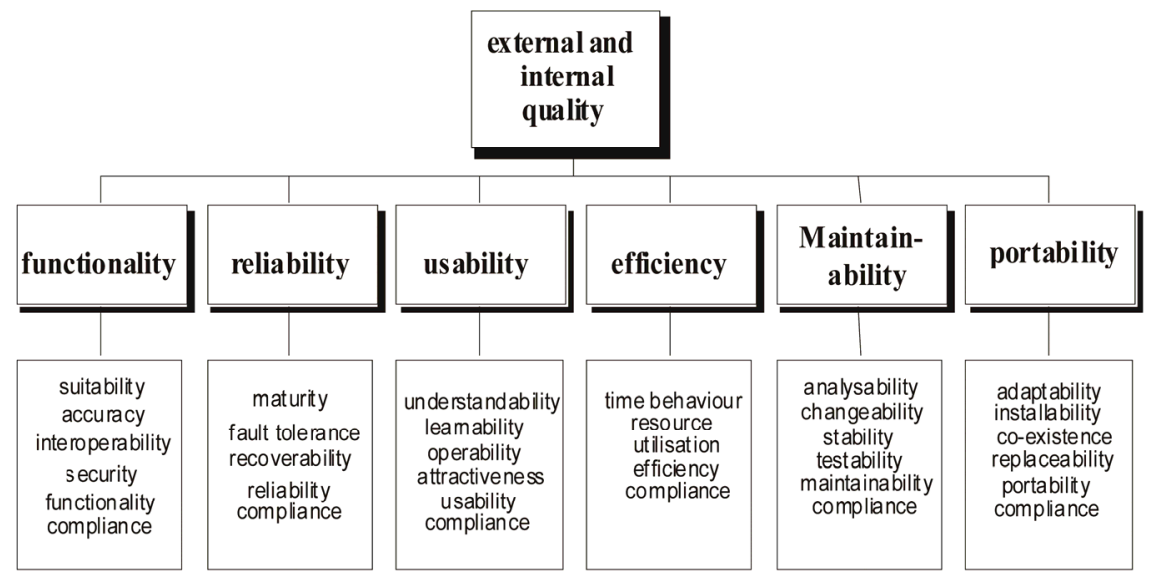

Figure 3. System and software product quality model ISO/IEC9126-1: 2001[7].

Table 2. Example of negative review from web-site.

\begin{tabular}{|c|c|c|c|c|c|c|c|c|c|c|c|c|c|}
\hline \multirow{2}{*}{$\begin{array}{l}\text { View point of Six } \\
\text { quality characteristics }\end{array}$} & \multirow{2}{*}{\multicolumn{2}{|c|}{ Category of negative review }} & \multicolumn{11}{|c|}{ Number of negative reviews (count) } \\
\hline & & & $\mathrm{S}_{1}$ & $\mathrm{~S}_{2}$ & $\mathrm{~S}_{3}$ & $\mathrm{~S}_{4}$ & $\mathrm{~S}_{5}$ & $\mathrm{~S}_{6}$ & $\mathrm{~S}_{7}$ & $\mathrm{~S}_{8}$ & $\mathrm{~S}_{9}$ & $\mathrm{~S}_{10}$ & $\mathrm{~S}_{\mathrm{i}}$ \\
\hline \multirow{2}{*}{ functionality } & $\begin{array}{l}\text { Number of Built-in } \\
\text { application software }\end{array}$ & $a 1_{i}$ & 0 & 0 & 1 & 0 & 0 & 0 & 0 & 0 & 0 & 0 & 0 \\
\hline & A Kind of OS & $a 2_{i}$ & 0 & 0 & 1 & 0 & 0 & 0 & 0 & 1 & 0 & 0 & 0 \\
\hline \multirow{3}{*}{ usability } & Easiness in seeing screen & $b 1_{i}$ & 14 & 3 & 11 & 3 & 3 & 11 & 2 & 0 & 2 & 6 & 3 \\
\hline & Easiness to use Keyboard & $b 2_{i}$ & 6 & 3 & 5 & 6 & 2 & 12 & 3 & 5 & 1 & 12 & 4 \\
\hline & Weight of body & $b 3_{i}$ & 5 & 0 & 8 & 0 & 2 & 1 & 0 & 1 & 2 & 1 & 0 \\
\hline \multirow{3}{*}{ readability } & Number of fault & $c 1_{i}$ & 1 & 0 & 1 & 1 & 0 & 4 & 0 & 0 & 0 & 0 & 0 \\
\hline & A production country & $c 2_{i}$ & 3 & 0 & 4 & 5 & 0 & 7 & 0 & 0 & 1 & 2 & 1 \\
\hline & Capacity of Battery & $c 3_{i}$ & 6 & 1 & 1 & 12 & 0 & 0 & 0 & 0 & 7 & 9 & 1 \\
\hline \multirow{2}{*}{ efficiency } & Transaction speed & $d 1_{i}$ & 2 & 0 & 3 & 3 & 0 & 1 & 1 & 4 & 0 & 0 & 1 \\
\hline & Drive time & $d 2_{i}$ & 13 & 0 & 0 & 8 & 0 & 3 & 0 & 2 & 1 & 1 & 0 \\
\hline portability & Number of USB port & $e 1_{i}$ & 7 & 1 & 2 & 0 & 1 & 0 & 1 & 0 & 0 & 3 & 3 \\
\hline maintainability & Customer support & $f 1_{i}$ & 1 & 1 & 0 & 0 & 0 & 0 & 1 & 0 & 1 & 1 & 0 \\
\hline \multicolumn{2}{|c|}{ Total number of Review } & $R C_{i}$ & 58 & 22 & 38 & 41 & 26 & 78 & 23 & 19 & 21 & 35 & 32 \\
\hline
\end{tabular}

$\mathrm{S}_{\mathrm{i}}$ : Example of target laptop personal computers (i: Number of sample product $(i=1-35)$ ). 
Table 3. Importance of customer needs by six quality characteristics.

\begin{tabular}{|c|c|c|c|c|c|c|c|c|c|c|}
\hline \multirow{2}{*}{$\begin{array}{l}\text { View point of Six } \\
\text { quality characteristics }\end{array}$} & \multirow{2}{*}{ Category of Questions } & & \multicolumn{6}{|c|}{ Samples of Customers } & \multirow{2}{*}{\multicolumn{2}{|c|}{$\begin{array}{c}\text { Weight: Importance } \\
\text { Ratio }\end{array}$}} \\
\hline & & & $\mathrm{U}_{1}$ & $\mathrm{U}_{2}$ & $\mathrm{U}_{3}$ & $\mathrm{U}_{4}$ & $\mathrm{U}_{5}$ & $\mathrm{U}_{\mathrm{n}}$ & & \\
\hline \multirow[t]{2}{*}{ functionality } & $\begin{array}{l}\text { Number of Built-in } \\
\text { application software }\end{array}$ & $a a a 1_{n}$ & 15 & 10 & 10 & 10 & 8 & 15 & \multirow[t]{2}{*}{$M$} & \multirow[t]{2}{*}{0.6350} \\
\hline & A Kind of OS & $a a a 2_{n}$ & 9 & 4 & 3 & 9 & 13 & 12 & & \\
\hline \multirow{4}{*}{ usability } & Easiness in seeing screen & $b b b 1_{n}$ & 4 & 2 & 6 & 3 & 5 & 6 & \multirow{4}{*}{$N$} & \multirow{4}{*}{0.7260} \\
\hline & Screen Size & $b b b 2_{n}$ & 5 & 3 & 14 & 8 & 6 & 5 & & \\
\hline & Easiness to use Keyboard & $b b b 3_{n}$ & 6 & 9 & 15 & 12 & 4 & 7 & & \\
\hline & Weight of body & $b b b 4_{n}$ & 8 & 6 & 9 & 7 & 11 & 11 & & \\
\hline \multirow{3}{*}{ readability } & Number of fault & $c c c 1_{n}$ & 3 & 5 & 4 & 1 & 12 & 8 & \multirow{3}{*}{$O$} & \multirow{3}{*}{0.7610} \\
\hline & A production country & $\operatorname{ccc} 2_{n}$ & 12 & 12 & 12 & 5 & 15 & 10 & & \\
\hline & Capacity of Battery & $c c c 3_{n}$ & 2 & 8 & 7 & 4 & 9 & 2 & & \\
\hline \multirow{2}{*}{ efficiency } & Transaction speed & $d d d 1_{n}$ & 7 & 7 & 8 & 3 & 10 & 4 & \multirow{2}{*}{$P$} & \multirow{2}{*}{1.0000} \\
\hline & Drive time & $d d d 2_{n}$ & 1 & 1 & 1 & 2 & 3 & 3 & & \\
\hline \multirow{2}{*}{ portability } & Number of USB port & eee $1_{n}$ & 13 & 11 & 13 & 11 & 7 & 14 & \multirow{2}{*}{$Q$} & \multirow{2}{*}{0.4440} \\
\hline & Number of Memory Slot & eee $2_{n}$ & 10 & 14 & 11 & 13 & 2 & 13 & & \\
\hline maintainability & Customer support & $f f f 1_{n}$ & 14 & 13 & 5 & 14 & 14 & 9 & $R$ & 0.5480 \\
\hline Performance & Price & $p p p 1_{n}$ & 11 & 15 & 2 & 6 & 1 & 1 & $V$ & 0.8740 \\
\hline
\end{tabular}

$\mathrm{U}_{\mathrm{n}}$ : Example of customers ( $\mathrm{n}$ : Number of customers $(\mathrm{n}=1-61)$.

target products from the degree of price and inherent attributes of product, and the study performs multiple regression analyses.

For performing a multiple regression analysis, the degree of observed total customer satisfaction of product has assigned to the objective variable, and price and inherent attributes of product has assigned to the explanatory variables.

The possibility of whether or not the degree of observed total customer satisfaction of products can be derived from the degree of price and inherent attributes of target product during the system design phase was verified.

Finally, the study discusses the validity of estimated prediction models based on the significance of the developed prediction model and possibility of application of proposed prediction model and approaches.

\subsection{Target Data}

In recent years, due to the explosion of the Internet, purchasing behaviours of customers have significantly changed. For example, an increasing number of customers order a product directly from an electric commerce site without visiting brick-and-motor shops while remaining at home. The degree of customer satisfaction is a measure use din marketing that represents how a product or service produced by a company meets or surpasses customer expectation. This study focuses on online reviews posted on the Internet, an effective alternative to face-toface interviews of customers, and uses the online negative reviews of a system product as data to investigate. This study collects and uses online reviews of products posted at a web-site, kakaku.com [13] as customer's expression of his/her dissatisfaction of system products. Table 2 shows the part of collection data concerning negative review from web-site, which total number of type of LPCs is 35 and total number of review is 457 .

From Table 2, this study counts the number of online negative reviews for each concrete category of interest of LPCs from the view point of the six quality characteristics. This study collects and classifies online negative reviews from the view point of the six quality characteristics in this manner. Furthermore, for each product, this study obtains the degree of importance for each of the six quality characteristics taking into account the interest of attribute of LPCs (i.e., weight for) correspond to the six quality characteristic as shown in Table 3. Table 3 shows the questionnaires and example of result of importance of quality needs for each six quality characteristics obtain from questionnaires.

The questionnaires asked customers the question of "in purchasing a LPC, what attributes are important?" and 
have the customers assign a numeric order number between 1 and 15 based on the importance;

The order number is 1 for the most important for the quality characteristic, and the weight for the six quality characteristics are normalized in the range from 0 to 1 .

This study quantitatively calculates the importance of customer needs for each quality characteristics.

For example, the importance of functionality as $M$ is obtained from the following Equation (1).

$$
\mathrm{M}=\frac{\sum_{\mathrm{n}=1}^{\mathrm{TN}}\left(\mathrm{ON}+1-\mathrm{aaa}_{\mathrm{n}}\right)+\sum_{\mathrm{n}=1}^{\mathrm{TN}}\left(\mathrm{ON}+1-\mathrm{aaa} 2_{\mathrm{n}}\right)}{\max (\mathrm{M}, \mathrm{N}, \mathrm{O}, \mathrm{P}, \mathrm{Q}, \mathrm{R}) \times \mathrm{TN} \times 2}
$$

\section{M: Importance ratio of Functionality (weight)} ON)

aaa1 $_{n}$ : Order number of importance $($ aaa1 $=1$ aaa2 $2_{n}$ Order number of importance $($ aaa2 $=1$ ON)

n: Number of customers $(n=1-T N)$

ON: Maximum order number $(\mathrm{ON}=15)$

TN: Total number of customers $(\mathrm{TN}=61)$

From Table 3, TN is the total number of customers, which total number of customers is 61 , and $p$ is the weight for the efficiency determined from the questionnaires.

This study also focuses on laptop computers (LPCs). Reasons for choosing LPCs are, at first, LPCs have attribute and characteristics that correspond to the six quality characteristics, and there is a large amount of data available on the non-functionality and non-quantitatively requirements on online review web-sites.
Table 1 shows the part of collection data concerning inherent attributes of LPCs from web-site, which total number of type of LPCs is 35. Inherent attribute refers to the degree to which attributes of target product have the intrinsic potential to satisfy stated and implied needs when LPCs is used under specified conditions. From the inherent point of view, Attribute of LPCs is product itself, in particular to shown in Table 1.

Above consideration, price is not inherent attribute but assigned attribute. If we wish to evaluate the customer satisfaction from the view point of product quality, we should use only inherent attribute of target product itself. Then, this study use only inherent attributes of target product without price.

\subsection{Degree of Customer Satisfaction}

Table 4 shows the parts of result of degree of the ob served customer satisfaction for each quality characteristics.

By applying the weight for each of the six quality characteristics, this study quantitatively calculates the degree of customer satisfaction for each six quality characteristics. For example, the degree of customer satisfaction for efficiency as DD is obtained as following Equations (2) and (3).

$$
\begin{gathered}
\mathrm{dd}_{\mathrm{i}}=\frac{\mathrm{d}_{\mathrm{i}} \times \mathrm{p}}{\mathrm{RC}} \\
\mathrm{DD}=1-\sqrt{\mathrm{dd}_{1}^{2}+\mathrm{dd}_{2}^{2}}
\end{gathered}
$$

This study quantitatively calculates the degree of ob-

\begin{tabular}{|c|c|c|c|c|c|c|c|}
\hline \multirow{3}{*}{$\begin{array}{l}\text { Number of } \\
\text { Sample } \\
\text { products }\end{array}$} & \multicolumn{7}{|c|}{ Degree of observed customer satisfaction } \\
\hline & Functionality & Usability & Reliability & Efficiency & Portability & Maintainability & Total \\
\hline & AA & $\mathrm{BB}$ & $\mathrm{CC}$ & $\mathrm{DD}$ & $\mathrm{EE}$ & $\mathrm{FF}$ & TS \\
\hline $\mathrm{S}_{1}$ & 1.0000 & 0.7993 & 0.9110 & 0.7732 & 0.9464 & 0.9906 & 2.2234 \\
\hline $\mathrm{S}_{2}$ & 1.0000 & 0.8600 & 0.9654 & 1.0000 & 0.9798 & 0.9751 & 2.3627 \\
\hline $\mathrm{S}_{3}$ & 0.9764 & 0.7231 & 0.9150 & 0.9211 & 0.9766 & 1.0000 & 2.2618 \\
\hline $\mathrm{S}_{4}$ & 1.0000 & 0.8812 & 0.7580 & 0.7916 & 1.0000 & 1.0000 & 2.2311 \\
\hline $\mathrm{S}_{5}$ & 1.0000 & 0.8849 & 1.0000 & 1.0000 & 0.9829 & 1.0000 & 2.3977 \\
\hline $\mathrm{S}_{6}$ & 1.0000 & 0.8482 & 0.9213 & 0.9595 & 1.0000 & 1.0000 & 2.3428 \\
\hline $\mathrm{S}_{7}$ & 1.0000 & 0.8862 & 1.0000 & 0.9565 & 0.9807 & 0.9762 & 2.3696 \\
\hline $\mathrm{S}_{8}$ & 0.9666 & 0.8052 & 1.0000 & 0.7646 & 1.0000 & 1.0000 & 2.2732 \\
\hline $\mathrm{S}_{9}$ & 1.0000 & 0.8963 & 0.7438 & 0.9524 & 1.0000 & 0.9739 & 2.2830 \\
\hline $\mathrm{S}_{10}$ & 1.0000 & 0.7209 & 0.7995 & 0.9714 & 0.9619 & 0.9843 & 2.2354 \\
\hline $\mathrm{S}_{\mathrm{i}}$ & 1.0000 & 0.8866 & 0.9664 & 0.9688 & 0.9584 & 1.0000 & 2.3615 \\
\hline
\end{tabular}
served total customer satisfaction from the view point of

Table 4. Degree of observed customer satisfaction.

Si: Example of target laptop personal computers ( $\mathrm{n}$ : Number of sample product $(\mathrm{i}=1-35)$ ). 
six quality characteristic included in the ISO/IEC9126 quality model.

The degree of observed total customer satisfaction is obtained based on the consideration of independency among six quality characteristics as following Equations (4) as shown in Table 4.

$$
\mathrm{TS}=\sqrt{\mathrm{AA}^{2}+\mathrm{BB}^{2}+\mathrm{CC}^{2}+\mathrm{DD}^{2}+\mathrm{EE}^{2}+\mathrm{FF}^{2}}
$$

\section{TS: Observed total customer satisfaction}

This study also predicts the degree of total customer satisfaction and price of product. The degree of predicting total customer satisfaction sis obtained by using inherent attributes of LPCs as following Equations (5). And, the degree of price of product by using inherent attributes of LPCs as following Equations (6).

$$
\mathrm{PS}=\mathrm{r}_{0}+\mathrm{r}_{1} \mathrm{xa}+\mathrm{r}_{2} \mathrm{xb}+\cdots \cdots+\mathrm{r}_{\mathrm{n}} \mathrm{xO}
$$

PS: Predicting total customer satisfaction

$\boldsymbol{r}_{n}$ : partial regression coefficient $(n=1-14)$

$$
\mathrm{PP}=\mathrm{r}_{0}+\mathrm{r}_{1} \mathrm{xa}+\mathrm{r}_{2} \mathrm{xb}+\cdots \cdots+\mathrm{r}_{\mathrm{n}} \mathrm{xO}
$$

PP: Predicting price of product

$\boldsymbol{r}_{n}$ : partial regression coefficient $(n=1-14)$

\section{Verification}

\subsection{Correlation Matrix between Observed Total Customer Satisfaction and Attributes}

Table 5 shows the result of correlation analysis among inherent attributes and observed "Price and total customer satisfaction" of LPCs. The correlations about "Price and some inherent attributes" are recognized. Also, the results of correlations between "total customer satisfaction and some inherent attributes" are recognized.

\subsection{Multiple Regressions Analysis among Observed Total Customer Satisfaction and Attributes}

Table 6 shows the three types of prediction models based on the consideration about the result of correlation analysis. From Table 6, multiple-regression analysis between an observed total customer satisfaction and the price and con cerning inherent attributes of each type of prediction model shows that the maximum value of the multipleregression coefficients and the determination coefficients are 0.5626 and 0.3165 , respectively as prediction model Type 02. In addition, maximum value of F-test is 2.6853. Since it is bigger than $5 \%$ significance level $\mathrm{F}_{0}=$ 2.5336 , this study confirms that there is significance in predicting the degree of total customer satisfaction.

The cause and effect relationship between the degree of observed total customer satisfaction and those corresponding inherent attributes of LPCs could be observed.

This study verified the validity of the introduced prediction models of quantitatively predicting total customer satisfaction using the inherent attributes of target LPCs.

\begin{tabular}{|c|c|c|c|c|c|c|c|c|c|c|c|c|c|c|}
\hline & CPU & $\begin{array}{c}\text { HDD } \\
\text { capacity }\end{array}$ & GPU & Resolution & $\begin{array}{l}\text { Weight } \\
\text { of body }\end{array}$ & $\begin{array}{l}\text { Drive } \\
\text { time }\end{array}$ & $\begin{array}{l}\text { Number } \\
\text { of USB } \\
\text { port }\end{array}$ & $\begin{array}{c}\text { Number of } \\
\text { memory } \\
\text { slot }\end{array}$ & $\begin{array}{l}\text { Production } \\
\text { country }\end{array}$ & $\begin{array}{l}\text { Clock } \\
\text { speed }\end{array}$ & $\begin{array}{c}\text { Cash } \\
\text { Memory } \\
\text { size }\end{array}$ & $\begin{array}{l}\text { Liquid } \\
\text { crystal } \\
\text { size }\end{array}$ & $\begin{array}{l}\text { Memory } \\
\text { capacity }\end{array}$ & $\begin{array}{c}\text { Capacity } \\
\text { of } \\
\text { SSD } \\
\text { Memory }\end{array}$ \\
\hline & $a$ & $b$ & $c$ & $d$ & $e$ & $f$ & $g$ & $h$ & $i$ & $j$ & $k$ & $m$ & $n$ & $o$ \\
\hline$T S$ & 0.292 & -0.122 & -0.056 & -0.125 & -0.140 & 0.234 & 0.077 & -0.435 & 0.148 & 0.193 & 0.042 & -0.128 & 0.166 & 0.200 \\
\hline$p p$ & 0.187 & 0.228 & 0.171 & 0.511 & 0.122 & 0.093 & 0.191 & -0.178 & 0.542 & 0.001 & 0.526 & 0.032 & 0.389 & 0.189 \\
\hline PMIN & 0.147 & 0.213 & 0.169 & 0.486 & 0.154 & 0.089 & 0.274 & -0.189 & 0.608 & 0.047 & 0.446 & 0.063 & 0.305 & 0.133 \\
\hline$P M A X$ & 0.192 & 0.214 & 0.155 & 0.473 & 0.089 & 0.086 & 0.117 & -0.152 & 0.443 & -0.029 & 0.521 & 0.008 & 0.401 & 0.204 \\
\hline
\end{tabular}

But, the cause and effect relationship between the de-

Table 5. Correlation matrix between TS and inherent attributes of LPCs.

\begin{tabular}{|c|c|c|c|c|c|c|}
\hline \multirow{3}{*}{$\begin{array}{l}\text { Model } \\
\text { Type }\end{array}$} & \multirow{3}{*}{$\begin{array}{c}\text { Prediction Models for TS } \\
\text { TS: Total Customer Satisfaction of Product Quality }\end{array}$} & \multicolumn{5}{|c|}{ Result } \\
\hline & & \multirow{2}{*}{$\begin{array}{l}\text { R: Multiple } \\
\text { correlation coefficient }\end{array}$} & \multirow{2}{*}{$\begin{array}{c}\mathrm{R}^{2} \text { : } \\
\text { coefficient of } \\
\text { determination }\end{array}$} & \multirow{2}{*}{ F Value } & \multicolumn{2}{|c|}{$\mathrm{F}_{0}(\mathrm{~m}, 34,0.05)$} \\
\hline & & & & & $\mathrm{m}$ & $\mathrm{F}_{0}$ \\
\hline Type 01 & $P S=r_{0}+r_{1} \times a+r_{6} \times f+r_{8} \times h+r_{10} \times j+r_{14} \times O$ & 0.5685 & 0.3232 & 2.2289 & 6 & 2.4205 \\
\hline Type 03 & $P S=r_{0}+r_{6} \times f+r_{8} \times h+r_{10} \times j+r_{14} \times o$ & 0.4521 & 0.2044 & 1.4902 & 5 & 2.5336 \\
\hline
\end{tabular}

$r_{n}$ : partial regression coefficient $(n=1-15)$.

Table 6. Result of multiple regression analysis for total customer satisfaction.

$r_{n}$ : partial regression coefficient $(\mathrm{n}=1-14)$. 
gree of observed total customer satisfaction and those corresponding prices of LPCs could not be observed.

Since consideration of above result, this study confirms that causal relationship are not exists among the observed total customer satisfaction and concerning price of sample products.

Table 7 shows the nine types of prediction models price based on the consideration about the result of correlation analysis shown in Table 5. From Table 7, multiple-regression analysis between the observed price of product and concerning inherent attributes of each type of prediction model shows that the maximum value of the multiple-regression coefficients and the determination coefficients are 0.7776 and 0.6046 , respectively as prediction model Type 11 .

In addition, maximum value of F-test is 11.4696 . Since it is bigger than $1 \%$ significance level $\mathrm{F}_{0}=4.0179$, this study confirms that there is significance in predicting the degree of price of LPCs.

The cause and effect relationship between the degree of observed price of product and those corresponding inherent attributes such as " $d, i, k, n$ " of LPCs could be observed. But, the cause and effect relationship between the degrees of observed price of product and those corre sponding inherent attributes such as " $a, f, h, o$ " of LPCs could not be observed.

Since consideration of above result, this study confirms that causal relationship are exists among the observed total price and those part of corresponding inherent attributes such as " $d, i, k, n$ ” of LPCs could be observed.

Also, the cause and effect relationships between the degree of observed "average and minimum price" of products and those corresponding inherent attributes are high.

But, the cause and effect relationships between the degrees of observed "maximum price" of products and those corresponding inherent attributes are low.

\section{Concluding Remarks}

Figure 4 shows the confirmed result of investigation based on the result of predicted price and total customer satisfaction. In order to understand easily, Figure 4 illustrated based on the result of multiple-regression analysis shown in Table 5. In the Figure 4, the arrow of the solid line shows that a factor and the relationship of the result were recognized from result of this analysis. On the other hand, the arrows of the dashed line have not confirmed the causal relationship based on the analysis of this study, but there is thought that there are relations from experience.

From Figure 4, it was admitted that peculiar inherent attribute of " $a, f, h, o$ " of a product had an influence on the total customer satisfaction of the product. Furthermore, it was admitted that peculiar assigned attribute of " $d, i, k$, $n$ " of a product had an influence on the price of product. On the other hand, the influence on price was not confirmed by from the inherent attribute of " $a, n, f, h, o$ " of product.

As for this, the inherent attributes of product has the influence on the cost, and it is thought that, as a result, inherent attributes of product may influence the price as shown in Figure 4.

It is thought that the degree of total customer satisfac-

Table 7. Result of multiple regression analysis for price of product.

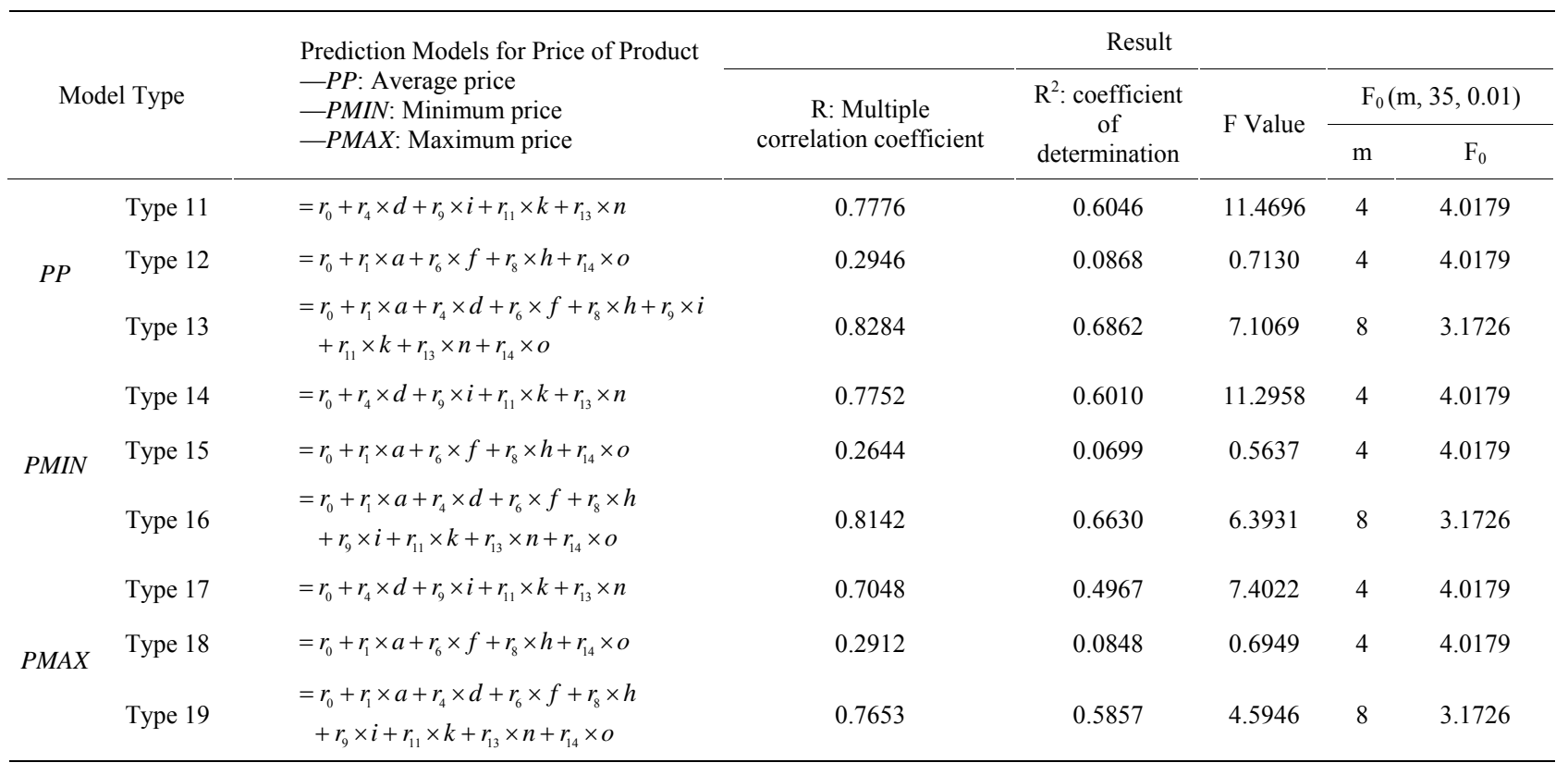




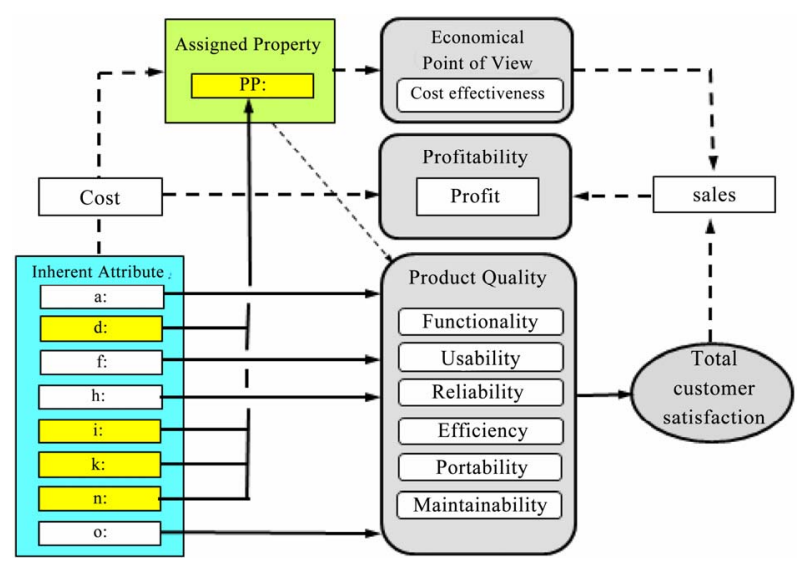

Figure 4. Result of predicting value of total customer satisfaction.

tion is not influenced by peculiar inherent attribute of " $d$, $i, k, n$ ", but the price of product is influenced by the peculiar inherent attribute of product from the above mentioned result.

In other words, this study confirmed that the price of product did not influence the total customer satisfaction of the product directly.

The reason of this, information from internet includes the unsatisfactory opinion for quality of the product mainly, and, it is thought that the opinion for price is not included.

Developers may improve total customer satisfaction by concentrating the financial resources into peculiar inherent attributes of product which is cause of increasing of total customer satisfaction, and controlling customer satisfaction and it is thought that, as a result, may realize the increase of sales.

-inherent attributes of product are contributes to the total customer satisfaction of product quality.

-inherent attributes of product are contributes to a price.

- price as assigned property of product may not contribute to total customer satisfaction of product quality, but may contribute to sales directly.

Developers improve total customer satisfaction by optimize a product quality and may finally increase a sales and profit based on the limited financial resources.

Thus, it is necessary to divide an improvement of price and product quality.

And, we may increase profit by the following methods:

- optimize a peculiar inherent attribute of a product to raise customer satisfaction.

- optimize a peculiar inherent attribute of a product to decrease a cost, and realize lower a price.

-improve total customer satisfaction and realize an improvement of sales.

In the future study, the author plans to study the influence of inherent attributes and application of proposed models to each six quality characteristics.

\section{Acknowledgements}

The authors are grateful to members of production system research office at Graduate School of Factory of Science and Engineering HOSEI University who their contributions and support to make the discussion.

\section{REFERENCES}

[1] ISO/IEC25000, "Software Engineering-Software Product Quality Requirements and Evaluation (SQuaRE) - Guide to SQuaRE," International Organization for Standardization, 2005.

[2] ISO/IEC25001, "Software Engineering-Software Product Quality Requirements and Evaluation (SQuaRE)—Planning and Management," International Organization for Standardization, 2007.

[3] ISO/IEC25030, "Software Engineering-Software Product Quality Requirements and Evaluation (SQuaRE)-Quality Requirement," International Organization for Standardization, 2007.

[4] ISO/IEC25040, "Software Engineering-System and Software Quality Requirements and Evaluation (SQuaRE)Evaluation Process," 2011.

[5] ISO/IEC25041, "Software Engineering-System and Software Quality Requirements and Evaluation (SQuaRE) Evaluation Guide for Developers, Acquirers and Independent Evaluators," 2012.

[6] K, Esaki1, "System Quality Requirement and Evaluation, Importance of Application of the ISO/IEC25000 Series," Global Perspective on Engineering Management, Vol. 2, No. 2, 2013.

[7] ISO/IEC9126-1, "Software Engineering-Product QualityPart1: Quality model," 2001.

[8] ISO/IEC25010, "Software Engineering-System and Software Quality Requirements and Evaluation (SQuaRE)System and Software Quality Model," International Organization for Standardization, 2011.

[9] B. W. Boehm, et al., "Quantative Ev. of Software Quality," 2nd ICSE, 1976, pp. 596-605.

[10] J. A. McCall, et al., "Factors in Software Quality," RADC TR-77369, 1977.

[11] K. Esaki, "Verification of Quality Requirement Method," American Journal of Operations Research, Vol. 2, No.1, 2013, pp.70-79.

[12] K. Esaki, Y. Ichinose and S. Yamada, "Statistical Analysis of Process Monitoring Data for Software Process Improvement and Its Application," American Journal of Operations Research, Vol. 3, No. 1A, 2012, pp.43-50.

[13] http://www.kakaku.com 